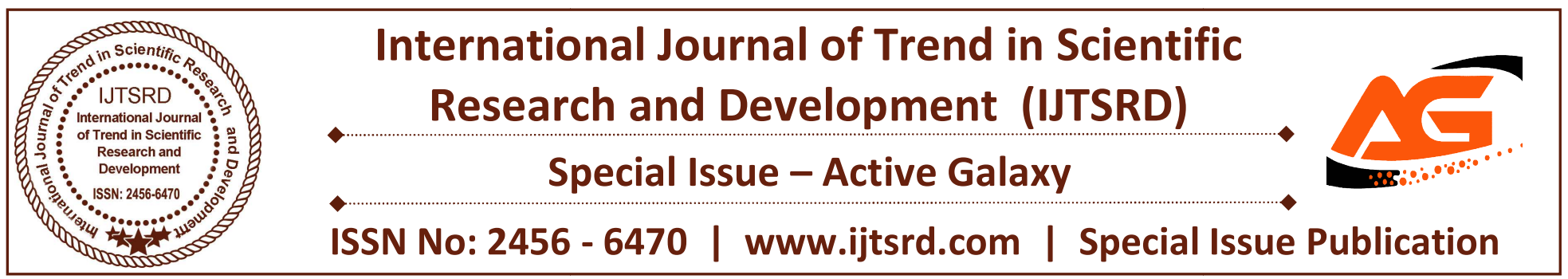

\title{
A Survey on Online Corporate Job Recruiting Process Using Cloud Computing
}

\author{
Mrs. S. Shanmugapriya ${ }^{1}$, Mr. Manikandan ${ }^{2}$, S. Karpaga Meenakshi ${ }^{3}$ \\ ${ }^{1,2}$ Assistant Professor, ${ }^{3} \mathrm{PG}$ Scholar \\ ${ }^{1}$ Department of Computer Science and Engineering, ${ }^{2,3}$ Department of Master of Computer Application \\ Vel Tech High Tech Dr. Rangarajan Dr. Sakunthala Engineering College, \\ Avadi, Chennai, India
}

\begin{abstract}
This project Online Corporate Job Recruiting process is an online website in which jobseekers can register themselves in online and apply for job. The HR of the companies as well as the employees working in the companies can also register in this website. Online corporate job recruiting process provides online help to the users all over the world. This website also make it possible for recruiters and companies to post their staffing requirements and view profiles of interested candidates. Not only the companies, but also the employees those who are working in the corporate companies can also host the details about the recruitment process that takes place in their companies. This project is aimed at developing a webbased and central recruitment Process system for the HR Group for a company. After registering in this website the candidates will get a pop-up notification about the recruitments. The additional characteristics of this project is that if a seeking job candidate registered in this website and if their college name is similarly equal to the college name of the registered employees, then they will get a mail immediately by saying that your college mate is seeking job kindly help them. So by this the job seekers can easily get a job.
\end{abstract}

Keywords: online test, reference, search jobs, resume upload, feedback, cloud.

\section{INTRODUCTION}

This project is aimed toward developing a web search Portal for the location Details for job seekers. The system is a web application which will be accessed throughout the organization and outdoors moreover with correct login provided. This technique may be used as a web Job Portal for job seekers. Job Seekers work ought to be ready to transfer their info within the kind of a $\mathrm{CV}$. Visitors/Company representatives work in may additionally access/search any info place up by Job aspirants .Cloud computing is employed as a site during this project. Cloud Computing is that the use of hardware and package to deliver a service over a network (typically the Internet). ... associate degree example of a Cloud Computing supplier is Google's Gmail. Gmail users will access files and applications hosted by Google via the net from any device. cloud computing is used to store and access knowledge and programs over the net rather than your computer's drive. The cloud is simply a trope for the net. Hence, in cloud we can able to store great deal of knowledge associated with job recruitments. Cloud will store these quite info in an exceedingly\} very secret manner. Nobody will access this website while not the permission of the user.The project can be hosted in the cloud so the users can make use of it anywhere at any time.

\section{EXISTING SYSTEM}

1. This paper aims within the creation of AN person, job search and leader agents that will use fuzzy preference rules to form a correct call in obtaining a listing of jobs supported the user's search criteria and conjointly feed the rating of the leader supported feedback submitted by the past and current staff that is exclusive and $1^{\text {st }}$ of its kind. 
All results applicable square measure organized supported a dynamic calculation of expected utility from highest to lowest and displayed because the job search listing.

2. This analysis aims to develop employment net portal for the scholars. The main aims of this portal square measure to attach to the industries and acts as a web achievement to support the scholars to search out the correct IT job when graduation. What is more, this technique enhances the understanding thought and importance of the work portal for college kids within the universities. A survey was conducted to spot the scholars issues with the present portal of the school and to assemble their necessities which may be incorporated in to the portal to be developed.

3. The purpose of the study was to develop a web achievement package that may facilitate the quick and correct choice of qualified candidates. It implies that the software would perform its operate effectively by choosing qualified applicants at intervals a shorter amount of your time. Thus, it was recommended that the system be adopted by University. Recommendations to enhance the package were conjointly offered.

4. The Job choice method in today's world economy is a frightening task for prospective staff notwithstanding their expertise level. It involves an in depth search of newspapers, job websites, human agents, etc, to spot associate employment chance that's perceived compatible to talents, anticipated remuneration and social desires. Search sites like look for, Academickeys.com, Careerbuilder.com, Job-hunt.org, Monster.com, etc permit prospective staff to register for employment.

5. This project is concerning the achievement method that is finished on-line. The achievement method here is handled by the system. This project can enable the person to use for employment within the company for the interested vacancy which might be accessible at the corporate. The person are having the account once registration and can be then referred to as the applied user. If he would be qualified, he would be interacting with the system for the updates. The project is formed for fulfilling the requests of the corporate managers so the achievement module is placed within the company's web site and therefore the users World Health Organization visit the web site will read the vacancies within the company and can be able to apply directly from remote place even.

6. E-Recruitment is that the latest trend within the enlisting method and it's been adopted in several organizations from massive to small-sized firms. during this article, there'll be associate introduction one-recruitment. there'll even be a discussion on the varied importances, disadvantages of e-recruitment. The study helps to research the trendsine-recruitment, e-recruitment strategies. Even Most organizations area unit already exploitation e-recruitment to post jobs and accept Resumes on the web, and correspond with the candidates by e-mail.

7. In this paper authors have planned a style of online accomplishment, that enables employers to post their job advertisements, that job seeker will see, once craving for jobs. This job portal is ready to capture job necessities supported trade wants. getting data and specific job skills became the most objectives for college kids within the universities. data is critical to create sophisticated selections, especially, in a important state of affairs. data and data management (KM) in any organization are crucial to relinquish it a competitive edge up today's difficult and globalised atmosphere.

8. Online applications for employment become customary and job offerings area unit announce in several job portals. However, there are a unit too several job portals to watch all of them if somebody is curious about a replacement job. we have a tendency to developed a image for desegregation data of various job portals into one meta-search engine. First, existing job portals were investigated and XML schemes were derived machine-driven from these portals. Second, translation rules for reworking every schema to a central HR-XML-conform schema were determined. 


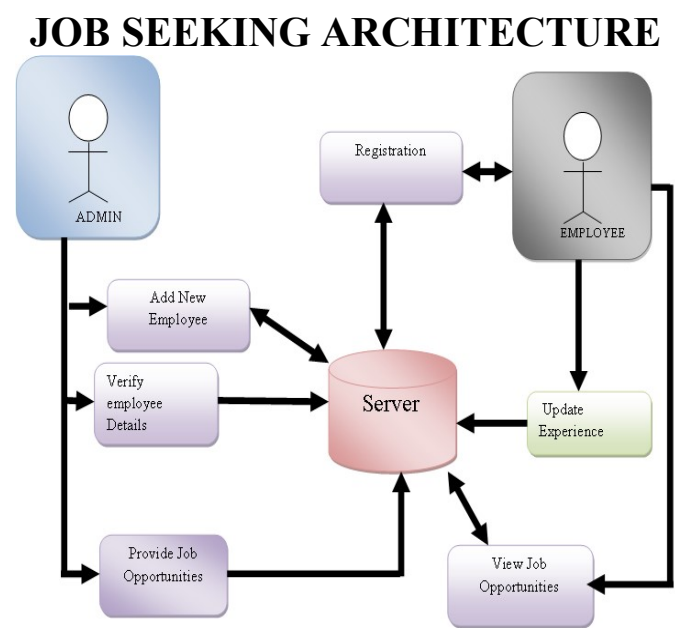

The jobseekers.com which is a online job portal website consists of three users they are job seekers, company, employee.At first they three have to register and login. After login into the website the jobseekers will fill the carrer details and they apply to the job which matches their profile. After applying to the job they will attend the aptitude test which is the first round of interview. The work of employee is to post the recruitment information that are placed in their companies. The job of company is to post the information which is related to the job and recruit the appropriate candidate.

\section{MODULES}

\section{REGISTRATION MODULE}

Job seekers, Employees and Companies can register in this website.

\section{LOGIN MODULE}

Job seekers, Employees and Companies who had registered in this website can login using their email Id and Password.

\section{JOB SEEKER MODULE}

Job seekers will give their full career details according to their qualification the name of the companies will be listed out and they can apply for a job.

\section{EMPLOYEE MODULE}

Employees who are working in the corporate companies can host the details about the recruitments that are placed on their companies.

\section{FAQ MODULE}

The job seekers will attend the first round of interview conducted by the companies and their test results will be displayed and if they get selected they will get the pop-up notification through email to attend the second round.

\section{REFERENCE MODULE}

The job seekers and Employees who are registered in this website belongs to the same college then the Employees will get a message that their college mate is seeking for a job.

\section{FEEDBACK MODULE}

In feedback module the users will check whether the given job recruitment information is valid or not. If the information is not valid then they will send the message that it is a strong information.

\section{CONCLUSION}

Online Job Portal is a intermediate between the people and the jobs. It connects the people with the real jobs. This project will be very useful for the job seekers who are searching job in corporate companies. It improves the functionality of the recruitment rather than manual in a company so it should improve the company standard also. This will provide better opportunities and guidance in future .In other job portal websites only job seeker and the higher officials login in the websites. But in this the employee those who are working in the company can also register and post the information about the job recruitment. The job seeker can search and apply for the job and they can also attend the online test if they are eligible for the company. If they passed in the online test their name will be shortlisted in that company so that they can attend the second round of interview by going directly to the company. In addition to all these process there is a special facility in this project, if the two of the registerd in this website are of same college means the working candidate who is already registered will get a sms notification that your collegemate is searching for the job. So, the job seeker can easily get the job with the help of the collegemate. 


\section{REFERENCES}

1. Job search system in android environment application of intelligent agents, Salathiel Bogle1 and Suresh Sankaranarayanan2,3, International Journal of Information Sciences and Techniques (IJIST) Vol.2, No.3, May 2012.

2. Development of a job web portal to improve education quality, Marjan Mansourvar and Norizan Binti Mohd Yasin, International Journal of Computer Theory and Engineering, Vol. 6, No. 1, February 2014

3. Effectiveness of Online Job Recruitment System: Evidence from the University of the East, Mary Grace G. Ventura1 and Rex P. Bringula2, IJCSI International Journal of Computer Science Issues, Vol. 10, Issue 4, No 1, July 2013.

4. IT Job Portal in Android, Radhika K. Rathi, Neha V. Londase, Rhucha D. Gangamwar, International Journal of Applied Information Systems (2249 0868) National Level Technical Conference "XPLORE 13”,vol.8,No.1,June 2014

5. Online job portal, Pavel Ray, IJCSI International Journal of Computer Science Issues ,vol.9,No 1,June 2013
6. Importance and Problems of E-Recruitment, Dr. R. Ramaabaanu1 \& M. Saranya2, International Journal of Research (IJR) Vol-1, Issue-9, October 2014 ISSN 2348-6848

7. Job Portal-A Web Application for Geographically Distributed Multiple Clients, Vivek Kumar Sehgal1, Akshay Jagtiani2, Meha Shah3 Anupriya Sharma4, Arpit Jaiswal5, and Dhananjay Mehta6, 2013 First International Conference on Artificial Intelligence, Modelling \& Simulation

8. Integration of Job Portals by Meta-search, J. Dorn , T.Naz, $14^{\text {th }}$ International Conf on Software Engineering and Knowledge Engineering vol 6,2015

9. E-recruitment : Aconceptual study, Prabjot Kaur, International Journal of Applied Research 2015; 1(8): 78-82 2015; 1(8): 78-82, 30-06-2015

10. A Online Job portal management system, Dr.Eng Fady Ibrahim, Omar Nizam AlDeen Yaseen Dergham Maxeem Deeb, Internationl Informatics, vol 5,October 2014 